\title{
Optimum Bored Pile Type Selection for Collapsible Soils
}

\author{
Sokolov NS* \\ Chuvash State University, Russia
}

*Corresponding author: Sokolov NS, Chuvash State University, Russia.

\begin{abstract}
The operational reliability of the constructed buildings and structures depends on the rationally accepted type of foundation. In cases of presence of structurally unstable engineering-geological elements (EGE) in foundation, the increased requirements are imposed on design and construction of foundations. For foundation beds composed of collapsible soils of natural occurrence, the main deteriorating indicators are the relative collapsibility coefficient $\varepsilon s e$ and the initial collapsible pressure Pse. The neglect of the influence of these indicators in most cases leads to deterioration in the reliable operation of the erected structures. The article presented here gives a case from geotechnical practice, when, a timely discovered error of not taking collapsible characteristics into account, made it possible to avoid an emergency situation at a structure under construction.
\end{abstract}

Keywords: Relative collapsibility coefficient; Initial collapsible pressure; Electric-discharge technology; Bored electric discharge (EDT) piles Abbreviations: عse: Relative collapsibility coefficient; Pse: Initial collapsible pressure; EDT: Electric-discharge technology

\section{Introduction}

Construction of facilities on structurally unstable foundation beds requires from designers, geotechnicians and builders to have a special approach when determining a buried structure type.

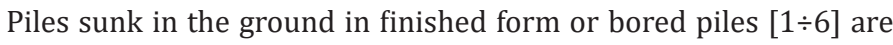
the most popular in modern geotechnical construction. Studies $[7 \div 15]$ proved that the most optimal characteristics for them are the following: specific bearing capacity, which characterizes pile bearing capacity per unit of its volume $q^{-}=F_{d} / V$, or specific design load $\mathrm{q}^{-1}$ characterizing the design load per unit of its volume $\mathrm{q}$ ${ }^{-}=\mathrm{N} / \mathrm{V}$. By this indicator, bored electric discharge (EDT) piles lead among the entire range of bored piles. The work presented here reviews a case from the practice of building a multistory residential building on a foundation bed of collapsible soils of the first type. The engineering and geological structure of construction site is characterized by the spread of a Quaternary cover of various genesis (tIV, dIII-IV, prIII, pdII-III) up to $15.2 \mathrm{~m}$ thick on the Upper Permian sandy-clayey rocks of the Tatarian stage $\left(\mathrm{P}_{3} \mathrm{t}\right)$. A summary brief engineering-geological section up to a study depth of $25.0 \mathrm{~m}$ (absolute elevation $116.9 \mathrm{~m}$ ) is shown in Table 1 below (Table 1 ).

\section{Methods}

A detailed lithological description of rocks is presented in geologic-lithological columns, and the conditions of occurrence are in engineering-geological sections. Figure 1 shows a typical engineering-geological section. The hydro geological conditions of the massif under consideration are characterized by the existing natural favorable drainage conditions, which are facilitated by sufficient surface slopes for surface runoff and the adjacent ravinegully network. This groundwater level (GWL) does not affect the conditions of construction and operation. For the survey period (October 2017), groundwater was discovered at a depth of $16.8 \mathrm{~m}$ to $22.6 \mathrm{~m}$, in the spot height range of $121.1-122.7 \mathrm{~m}$. The aquifer is free flowing. GWL is timed to the Upper Permian sandy formations $\mathrm{P}_{2 \mathrm{t}}$. The standing water level corresponds to the appeared one. The aquifer is fed due to the infiltration of atmospheric precipitation, 
and in the future, due to leaks from water-carrying communications. Unloading occurs generally to the north-towards the Volga and Shupashkarka river valleys, as well as into the nearest ravines and gullies adjacent to the site from the northwest and south, being at the same time the tributaries on the right of the Shupashkarka river. In the future, after the development of a micro district, the territory is potentially wetland area as a result of planned civil construction, as well as due to the widespread use of pile foundations (barrage effect). Man caused flooding will develop in the form of separate lenses and domes around emergency leaks from water-carrying utilities. According to the engineering-geological structure of the site and the lithological features of the soils, as well as according to laboratory tests, 7 engineering-geological elements (EGE) were identified. EGE No. 1-man maid soil: loam of semisolid and lowplastic consistency (tIV); -

Table 1: A summary brief engineering-geological section up to a study depth of $25.0 \mathrm{~m}$ (absolute elevation $116.9 \mathrm{~m}$ ).

\begin{tabular}{|c|c|c|c|c|}
\hline Stratigraphical Index & EGE No. & Description & Manner of Occurrence & Thickness, M \\
\hline tIV & 1 & $\begin{array}{l}\text { Man-made soil is loam with the following characteristics: brown, } \\
\text { brownish broccoli-brown, remolded with a soil layer and contain- } \\
\text { ing rare inclusion of building material (sand, debris), semisolid } \\
\text { and low-plastic. }\end{array}$ & Local & $0.5-1.2 \mathrm{~m}$ \\
\hline dIII-IV & 2 & $\begin{array}{l}\text { Loam is heavy, brown, with a touch of aleuritic dust along cracks, } \\
\text { with rare humus stains, mostly semisolid, in some areas up to } \\
\text { low-plastic consistency. }\end{array}$ & Areal & $0.6-2.0 \mathrm{~m}$ \\
\hline prIII & 3 & $\begin{array}{l}\text { Loam is light, turning into sandy loam, brown, yellowish brown, } \\
\text { macroporous, collapsible, indistinctly layered, of hard consisten- } \\
\text { cy. }\end{array}$ & Areal & $2.6-10.4$ \\
\hline prIII & 4 & $\begin{array}{l}\text { Loam is light, brown, yellowish-brown, indistinctly layered, local- } \\
\text { ly collapsible, slightly ferruginized, predominantly of low-plastic } \\
\text { consistency, in areas up to high-plastic. }\end{array}$ & $\begin{array}{l}\text { Local, in areas of pos. } \\
\qquad 1,3\end{array}$ & $0.8-7.5 \mathrm{~m}$ \\
\hline pdII -III & 5 & $\begin{array}{l}\text { Loam is light, grayish brown,gray, greenish-gray,with bunches of } \\
\text { humus and ferruginization, often arenaceous in the bottom,with } \\
\text { the bedrock debris inclusionof up to 5\%, low-plastic consistency. }\end{array}$ & $\begin{array}{c}\text { Areal, in the bottom of } \\
\text { loess loams }\end{array}$ & $1.1-5.3 \mathrm{~m}$ \\
\hline $\mathbf{P}_{3} \mathbf{t}$ & 6 & $\begin{array}{l}\text { The sand is polymictic, uneven-grained: from silty to medium } \\
\text { size, greenish-gray, brown, tobacco-brown, clayey, with thin lay- } \\
\text { ers of clay, aleurite, sandstone } 5-20 \mathrm{~cm} \text { thick, in terms of moisture } \\
\text { content - low moisture, saturated with water below GWL. }\end{array}$ & Areal & $5.1-14.4 \mathrm{~m}$ \\
\hline $\mathbf{P}_{3} \mathbf{t}$ & 7 & $\begin{array}{c}\text { Clay is light, reddish-brown, red, aleuritic, arenaceous in some } \\
\text { areas, less often marly, manganese along cracks, predominantly of } \\
\text { solid consistency. }\end{array}$ & Lensoid and embedded & $\begin{array}{l}\text { Penetrated thick- } \\
\text { ness } 0.2-3.0 \mathrm{~m}\end{array}$ \\
\hline
\end{tabular}

EGE No. 2-heavy semisolid and low-plastic loam (dIII-IV); -

EGE No. 3-light loam, turning into sandy loam, loess-like, solid consistency (pr III); -

EGE No. 4-light loam, loess-like, low-plastic to high-plastic (pr III); -

EGE No. 5-light, low-plastic loam (pdII-III); -

EGE No. 6-Sand of different grains, medium density, mostly lowmoisture, up to saturated with water in the bottom $\left(\mathrm{P}_{3} \mathrm{t}\right)$; -
EGE No. 7-light clay, aleuritic, with frequent interlayers and lenses (up to $0.1 \mathrm{~m}$ ) of aleurite, mostly of solid consistency $\left(\mathrm{P}_{3} \mathrm{t}\right)$. In order to clarify the boundaries of a selected EGE, to assess their spatial homogeneity, to obtain initial data for the calculation of possible piled foundations, static sounding was performed at 9 points to a depth of $19.5 \mathrm{~m}$. The results are according to static sounding and charts of soil resistivity under the probe cone $\left(\mathrm{q}_{3^{\prime}}\right.$ $\mathrm{MPa})$ and soil resistivity along the lateral surface of the probe $\left(\mathrm{f}_{\mathrm{s}^{\prime}}\right.$ $\mathrm{kPa})$. The values of resistivity $\left(\mathrm{q}_{3}\right)$, averaged over the selected EGE, are shown in Table 2 (Table 2).

Table 2: The values of resistivity $\left(q_{3}\right)$, averaged over the selected EGE.

\begin{tabular}{|c|c|c|c|c|c|c|c|}
\hline \multirow[t]{2}{*}{ EGE No. } & \multicolumn{4}{|c|}{$\mathrm{q}_{3}$ values, MPa } & \multicolumn{3}{|c|}{$\begin{array}{l}\text { Standard values of soil characteristics are according to Code of Practice } \\
\text { 11-105-97, 'Engineering Geological Site Investigations for Construction' } \\
\text { (Russian designation CП 11-105-97). }\end{array}$} \\
\hline & Number of Findings & from & to & standard & $\mathrm{E}_{0}, \mathrm{MPa}$ & c, kPa & $\varphi$, deg. \\
\hline 2 & 91 & 0.1 & 2.4 & 0.9 & 6 & 17 & 19 \\
\hline 3 & 471 & 0.5 & $8.8^{*}$ & $3.0^{* *}$ & 21 & 23 & 21 \\
\hline 4 & 195 & 0.1 & $3.0^{*}$ & $0.7^{* *}$ & 5 & 14 & 16 \\
\hline 5 & 149 & 0.4 & $4.1^{*}$ & 1.4 & 10 & 19 & 20 \\
\hline 6 & 338 & 3.1 & $19.5^{*}$ & $8.6^{* *}$ & 24 & - & 32 \\
\hline 7 & $167^{* *}$ & 1.1 & 8.3 & 2.6 & 18 & 38 & 19 \\
\hline
\end{tabular}


The soils characteristics obtained from the results of static sounding correspond to the natural state at the time of the survey. To justify the optimal type of buried structures, the C 15.30-10.1 type driven piles with a length of $15 \mathrm{~m}$ (but experiments with sinking piles of more than $15 \mathrm{~m}$ long do not reach the design elevation) and CP-17-30, CP-18-30, CP-20-30 type bored electric discharge (EDT) piles were used. According to the accomplished geotechnical calculations, 644 piles sunk by driving with a total molding of 9660,0 lin $\mathrm{m}$ (see Figure 2) or 403 electric discharge (EDT) piles with a total molding of 7120 lin m (see Figure 3) were designed in the pile field (Figures 1-3).

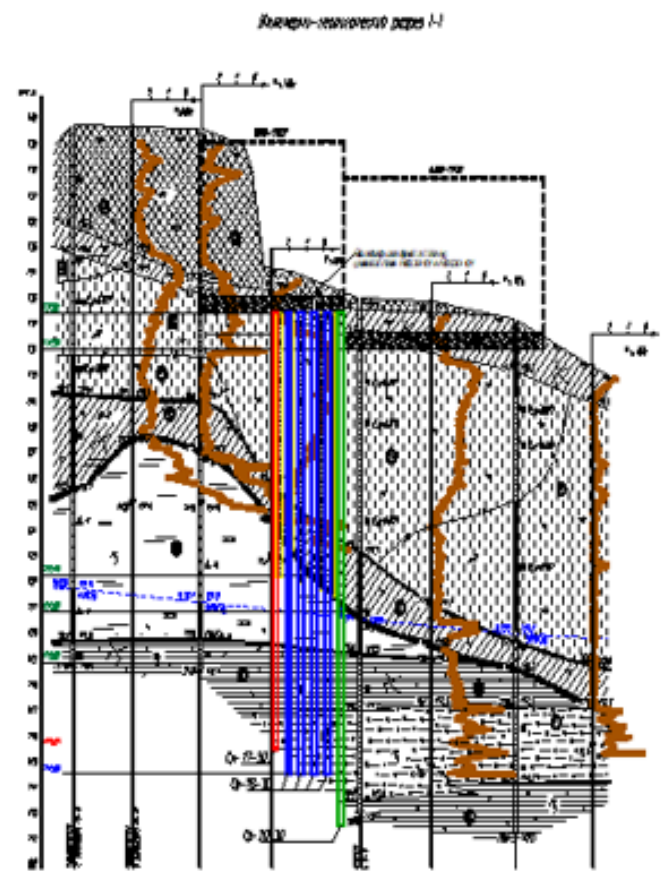

Figure 1: Engineering-geological section with reference of bored injection piles.

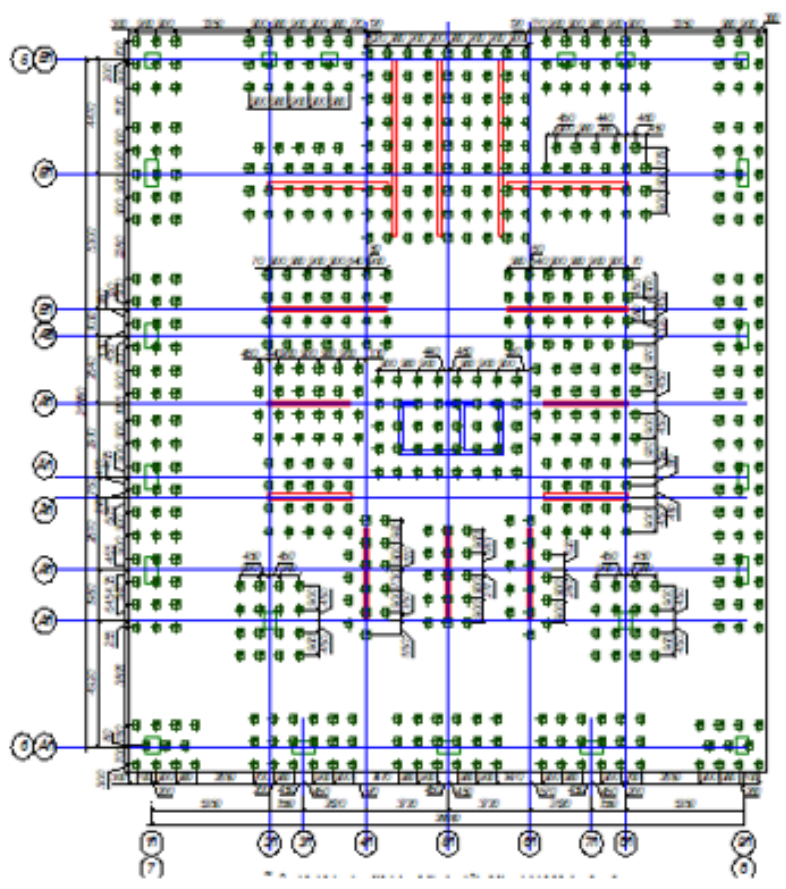

Figure 2: Pile field made of type $C$ 15.30-10.1 driven piles. 


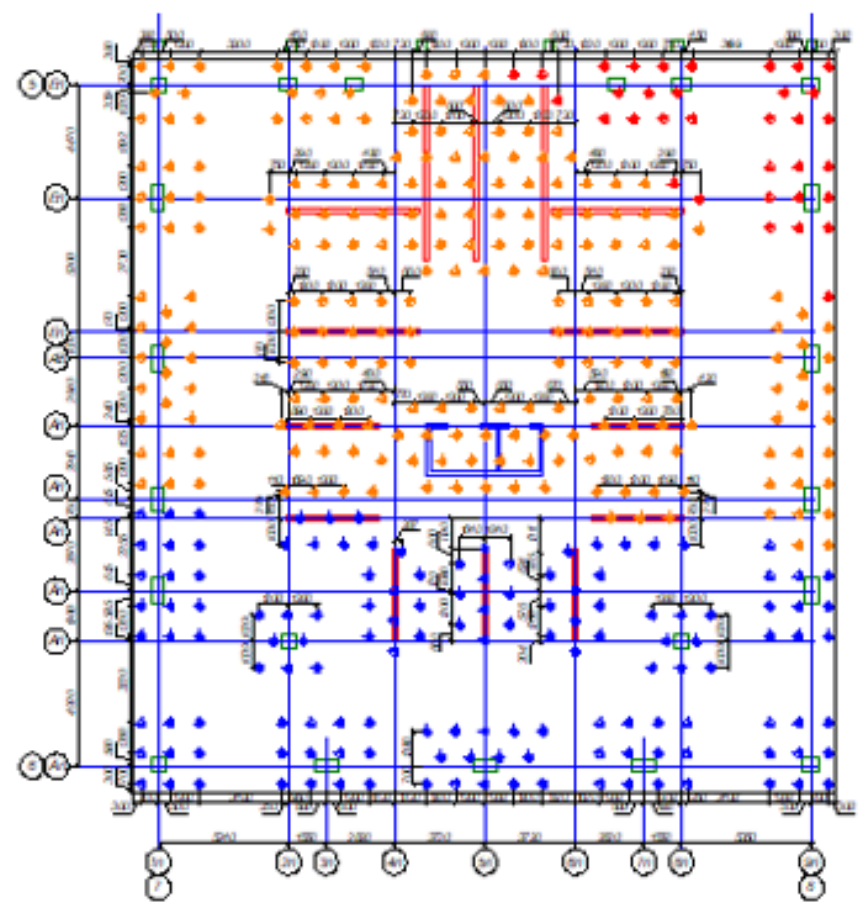

Figure 3: Pile field made of bored electric discharge (EDT) piles.

In terms of technical and economic indicators, the cost of electric discharge piles turned out to be lower than that of the driven piles. This is primarily due to the fact that both options involve drilling operations. In the first option, they are necessary for the device of pilot holes to facilitate pile driving, and in the second option, drilling is an obligatory element of the technological cycle. Therefore, as a technically justified option and an economically viable option, a pile field of 17.0; 18.0; 20.0-meter-long bored electric discharge (EDT) piles were accepted. The 'Project - Experimental Site - Real Project' interactive design principle/5/ was used at the facility. Static tests of two bored injection piles for vertical pressing load were carried out. The preparation of the base before the research was carried out in conformity with GOST 5686-2012 Soils. Field Test Methods by Piles according to technology for collapsible soils with preliminary soaking of soils around the tested piles. It should be noted that to minimize negative friction and to increase the bearing capacity of electric discharge (EDT) piles, No. 101 pile was made with two widening, and No. 25 pile with three widening. In works [4-15] it is proved that widening increases bearing capacity of bored piles. Moreover, each widening adds a $20-30 \%$ gain.

The work on testing the two electric discharge (EDT) piles, No. 101, 25, with increasing statically pressing load was carried out in accordance with GOST 5686-2012 Soils. Field Test Methods by Piles. The stages of load were imposed on the piles with a ЦС200 $\Gamma 160$ hydraulic jack (ЦС is Russian designation for Power Cylinder; $\Gamma$ is Russian designation for Hydraulic). The registration of the loads values was carried out using a standard pressure gauge of
$1000 \mathrm{kgf} / \mathrm{cm}^{2}\left(10^{5} \mathrm{kPa}\right)$ with a scale division of $20 \mathrm{kgf} / \mathrm{cm}^{2}(2000$ $\mathrm{kPa}$ ). Observations of the vertical bored electric discharge (EDT) piles displacements were carried out using two dial indicators with an accuracy of $0.005 \mathrm{~mm}$ until the conditional stabilization of deformation. The criterion for conditional stabilization of deformation is assumed to be the settlement rate of a pile at a given stage of loading, which does not exceed $0.1 \mathrm{~mm}$ over the last hour of observation. Based on the results of control tests, the following representations were compiled: charts of the settlement dependence on load S = f(P) (see Figure 4a,4b); charts of the settlement change over time for individual stages of loads $\mathrm{S}=\mathrm{f}(\mathrm{t})$; tables of test results. The ultimate resistance $F_{\mathrm{u}}$ to the vertical pressing load is assumed to be a load equal to or less than settlement determined by the formula: $S=\zeta S_{u^{\prime}{ }^{\prime} t^{\prime}}$ where $S_{u^{\prime} m t}$ is the limiting value of the average settlement of the projected building or structure foundation, established according to the Code of Practice СП 22.3330.2011 Revised Edition of SNiP 2.02.01-83 Soil Bases of Buildings and Structures; $\zeta$ is the coefficient of transition from the limiting value of the building or structure average foundation settlement $S_{u^{\prime} m t}$ to the pile settlement, obtained during static tests with conditional stabilization (fading) of settlement, equal to 0.2 .

\section{Results}

Calculated load on a pile is determined by the formula: $N=\frac{F_{d}}{\gamma_{k}}$ , where $\gamma_{\mathrm{K}}$ is a dependability coefficient equal to 1.2 for static tests of piles for vertical pressing load. Table 3 below shows the research results (Table 3 ). 
Table 3: Research results.

\begin{tabular}{|c|c|c|c|}
\hline Test Pile & Item & Test Pile No. 101 & Test pile No. 25 \\
\hline \multicolumn{2}{|r|}{ Soils cut through by a pile } & $\begin{array}{c}\text { EGE - } 2 \text { Heavy, semisolid, low-plastic loam;EGE } \\
-3 \text { Light, loess loam of semisolid consisten- } \\
\text { cy;EGE - } 5 \text { Light, low-plastic loam;EGE - } 8 \text { Me- } \\
\text { dium density dust sand;EGE - } 6 \text { Light aleuritic } \\
\text { clay. }\end{array}$ & $\begin{array}{c}\text { EGE - } 2 \text { Heavy, semisolid, low-plastic } \\
\text { loam;EGE - } 3 \text { Light, loess loam of semisol- } \\
\text { id consistency;EGE - } 5 \text { Light, low-plastic } \\
\text { loam;EGE - } 8 \text { Medium density dust sand;EGE } \\
\text { - } 6 \text { Light aleuritic clay. }\end{array}$ \\
\hline \multicolumn{2}{|c|}{ Soils under the pile lower end } & EGE - 7 clayey, solid aleurite & EGE - 7 clayey, solid aleurite \\
\hline \multirow{5}{*}{$\begin{array}{l}\text { Research } \\
\text { results }\end{array}$} & Max. load, kN & 1044 & 1450 \\
\hline & Settlement at max. load, mm & 9.64 & 10.16 \\
\hline & Bearing capacity, kN & 1044 & 1276 \\
\hline & Settlement at bearing capacity, $\mathrm{mm}$ & 9.64 & 7.29 \\
\hline & Design load, kN & 870 & 1063 \\
\hline \multicolumn{2}{|r|}{ Specified test load, kN } & 900 & 900 \\
\hline \multicolumn{2}{|r|}{ Specified design load, kN } & 600 & 600 \\
\hline \multicolumn{2}{|c|}{ Percentage increase in bearing capacity $\mathrm{F}_{\mathrm{d}}$} & $45 \%$ & $77 \%$ \\
\hline \multicolumn{2}{|c|}{ Number of widening along a pile shaft } & 2 & 3 \\
\hline
\end{tabular}

\section{Conclusion}

In the complex engineering and geological conditions under consideration, in the presence of collapsible soils of the first type and significant thickness, on the basis of a technical and economic comparison of two types of buried structures, the bored electric discharge (EDT) piles with multiple widening turned out to be the most effective (Figure 4).

a)
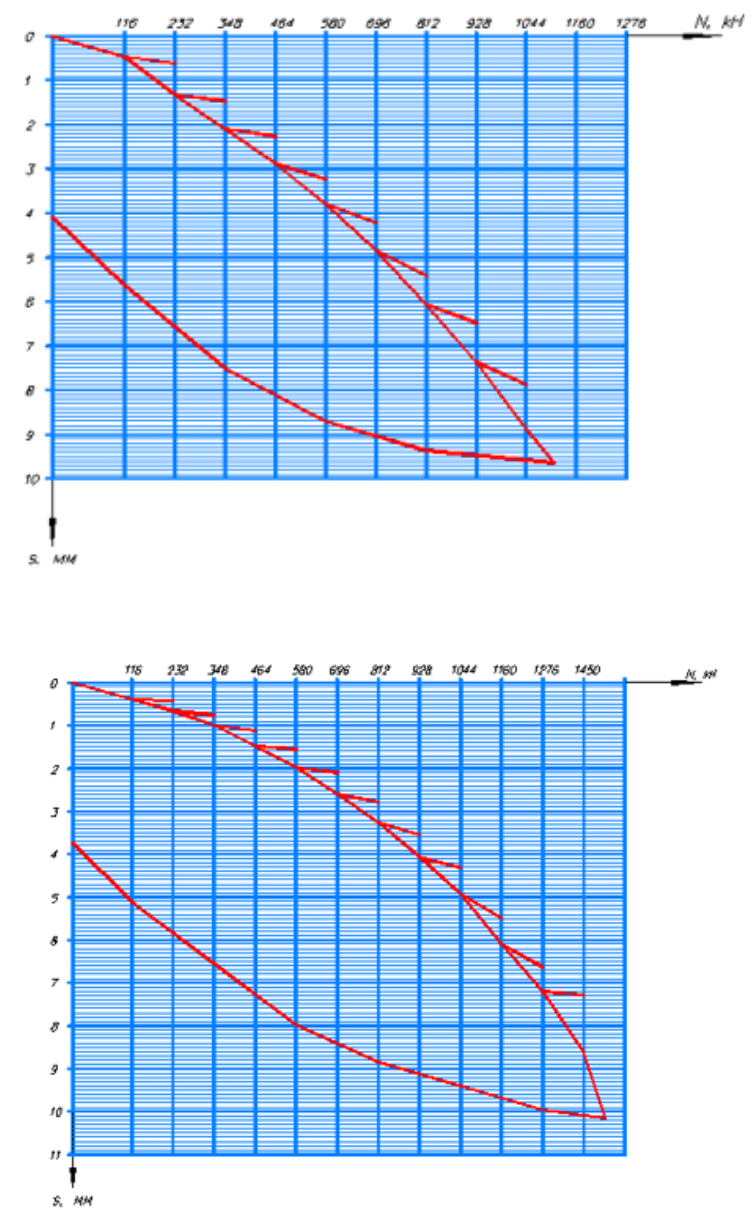

Figure 4: Charts of an electric discharge pile settlement S dependence on the load N: a-pile No. 101; b-pile No. 25. 


\section{Acknowledgment}

None.

\section{Conflict of Interest}

No conflict of interest.

\section{References}

1. Eliches VA, Mangushev RA, Nikiforova NS (2012) Experience of Development of Russian Megacities Underground Space. Soil Mechanics and Foundation Engineering 2: 17-20.

2. Ulickij VM, Shashkin AG, Shashkin KG (2010) Geotechnical Support of Urban Development. St. Petersburg, Georeconstruction Publ P. 551.

3. Razvodovsky DE, Chepurnova AA (2016) Assessing the Impact of Underpinning of Building Foundations Using the Jet-Grouting Technology on Its Settlements. Industrial and Civil Engineering 10: 6472.

4. Sokolov NS, Sokolov SN, Sokolov AN (2017) Fine Concrete as a Structural Building Material of Bored-Injection Piles EDT. Construction Materials Russia 5: 16-20.

5. Ulickij VM, Shashkin AG, Shashkin KG (2012) Geotechnical Guide (Guide to Basements, Foundations and Underground Structures). St. Petersburg, P. 284.

6. Sokolov NS (2018) One of the geotechnical technologies to strengthen the foundation base in constraint environment in the addition of 4 floors. 18 international multidisciplenary scientific GeoConference SGEM 2018 Albena Resort SPA Bulgaria.
7. Sokolov NS (2018) Ground Ancher Produced by Electric Discharge Technology, as Monolithic Reinforced Concrete Structure. Key Engineering Materials 771: 76-81.

8. Sokolov NS (2018) Use of the Piles of Effective Type in Geotechnical Construction. Key Engineering Materials 771: 71-74.

9. Sokolov NS (2018) One of Geotechnological Technologies for Ensuring the Stability of the Boiler of the Pit. Key Engineering Materials 771: 5769

10. Sokolov NS (2018) One of approaches to solve the problem of increasing the bearing capacity of bored piles. Construction Materials Russia 5: 4448.

11. Sokolov NS, Sokolov SN, Sokolov AN, Ryabinov VMO (2017) About bored injection piles with adjustable bearing capacity according to soil. Housing Construction 8: 34-38.

12. Sokolov NS, Nikiforova IV (2017) Construction and territorial development of the landslide slopes of the Cheboksary reservoir. Housing Construction 9: 13-20.

13. Sokolov NS (2017) Foundation with increased bearing capacity using bored electric discharge piles with multiple widening. Housing Construction 9: 25-29.

14. Sokolov NS (2018) Electro-impulse Device for Installation of BoredInjection Piles. Housing Construction 1-2: 62-66.

15. Sokolov NS, Viktorova SS, Smirnova GM, Fedoseeva IP (2017) BoredInjection EDT Pile as a Buried Reinforced Concrete Structure. Construction Materials Russia 9: 47-50. 